\title{
Aglomerações Industriais como Focos de Políticas
}

\author{
Industrial clusters as policies focuses
}

WILSON SUZIGAN*

RESUMO: Este artigo, escrito para um discurso, está dividido em duas partes. A primeira parte revisa a literatura sobre clustering industrial, com foco nas implicações políticas. Argumenta que a complexidade teórica, que dificulta a formalização do assunto, e a falta de trabalho empírico não autorizam argumentos simplistas a favor ou contra intervenções políticas. Por essas razões, as implicações políticas ainda não são totalmente exploradas na literatura. A segunda parte do artigo sugere uma agenda de pesquisa para o estudo de aglomerados industriais no Brasil, incluindo a produção de evidências estatísticas, trabalho empírico e estudos de caso como base para a elaboração de diretrizes de políticas.

PALAVRAS-CHAVE: Clustering industrial; política industrial; geografia econômica; localização da firma.

ABSTRACT: This paper, written as a keynote speech, is divided in two parts. The first part reviews the literature on industrial clustering focusing on policy implications. It argues that the theoretical complexity, which renders the subject difficult to formalize, and the want of empirical work do not authorize simplistic arguments pro or against policy interventions. For these reasons, policy implications are not yet fully explored in the literature. The second part of the paper suggests a research agenda for studying industrial clusters in Brazil, including the production of statistical evidence, empirical work and case studies as bases for designing policy guidelines.

KEYWORDS: Industrial clustering; industrial policy; economic geography; firm location. JEL Classification: L60; O33; R23; R32.

\section{INTRODUÇÃO}

Escolhi como tema desta aula um assunto que, nos últimos anos, vem sendo objeto de importantes desenvolvimentos teóricos e de produção de novas evidências estatísticas: a localização da produção no espaço geográfico. Em particular, dentro

\footnotetext{
* Professor do Instituto de Economia da Universidade Estadual de Campinas - IE-UNICAMP e pesquisador do NEIT - Núcleo de Economia Industrial e da Tecnologia, IE/UNICAMP, Campinas/SP, Brasil. E-mail: wsuzigan@gmail.com. Orcid https://orcid.org/0000-0002-2193-4756.
} 
desse tema geral, interessa-me a literatura que, recuperando as contribuições originais de Alfred Marshall, discute as razões pelas quais certas atividades, e mais especificamente atividades industriais, tendem a aglomerar-se em espaços geograficamente delimitados. E mais especificamente ainda, dentro desse sub-tema, vou focalizar o estado da arte da discussão sobre implicações de políticas.

$\mathrm{O}$ que me motivou? Em primeiro lugar, os próprios desenvolvimentos teóricos, que me atraíram seja por sua novidade, combinada com a recuperação de algumas das contribuições das tradicionais teorias de desenvolvimento econômico, seja por mostrarem uma convergência de vários enfoques com distintas fundamentações. Em segundo lugar, a motivação veio também do interesse que me despertou desenvolver estudos nessa área aplicados ao Brasil, especialmente pela oportunidade de discutir políticas com foco local como alternativa a políticas de âmbito nacional.

Como vou abordar o tema?

Não pretendo fazer resenha abrangente, nem crítica ou avaliação científica. Meu objetivo é, como usuário de teorias e, acima de tudo, satisfazendo uma espécie de cacoete, examinar a literatura em busca de argumentos que fundamentem políticas públicas orientadas a consolidar aglomerações industriais como polos geradores de crescimento, em prego, renda, desenvolvimento tecnológico e exportações. Por que políticas com foco em aglomerações industriais? Por duas razões: primeiro, pela falta de perspectivas para políticas industriais de âmbito nacional devido a restrições bastante conhecidas, desde as de cunho político-ideológico até as relacionadas a acordos e regulações de comércio internacional e de integração econômica regional, passando por restrições macroeconômicas, regulações internas, questões regionais e outras. A segunda razão é a de que, em contraste, é possível vislumbrar amplas perspectivas para políticas de cunho local/regional a partir de desenvolvimentos teóricos em várias abordagens, de evidências estatísticas sobre industrial clustering, de brechas deixadas a essas políticas nas regulações internacionais, mesmo quando impliquem subsídios, e de melhor trânsito político por atenderem a demandas locais e regionais.

Assim, de maneira muito simples e sem qualquer pretensão de originalidade, e lembrando sempre que o foco é sobre implicações de políticas, vou numa primeira parte discorrer livremente sobre a complexidade teórica do tema, procurando deixar claro que essa complexidade desautoriza argumentos simplistas pró ou contra intervenções de política, e que em termos empíricos os desafios são enormes e pouco se fez até agora. Ao abordar esses problemas - complexidade teórica e desafios empíricos -, vou argumentar que as implicações de políticas, embora reconhecidamente relevantes, são extremamente controversas e têm sido pouco exploradas na literatura. Depois, numa segunda parte, vou sugerir uma agenda de pesquisa sobre o tema, aplicada ao Brasil. 


\section{AGLOMERAÇÕES INDUSTRIAIS: TEORIA, EVIDÊNCIAS ESTATÍSTICAS E IMPLICAÇÕES DE POLÍTICAS}

Há várias abordagens ao tema de industrial clustering, incluindo: (1) as que se inspiram na experiência dos distritos industriais italianos ou europeus de modo geral;(2) as que se baseiam na natureza localizada da inovação tecnológica na dinâmica industrial; (3) as que se fundamentam na ciência regional para estabelecer relação entre geografia econômica e desempenho industrial; (4) as que focalizam as estratégias das empresas em busca de vantagens competitivas geograficamente restritas. Mas sem dúvida a mais influente é (5) a abordagem da nova geografia econômica, e é desta que vou me ocupar mais demoradamente.

Um dos desenvolvimentos mais importantes da teoria econômica desde o início dos anos 90 foi, de fato, o da nova geografia econômica (NGE), que Paul Krugman chamou de quarta onda da revolução dos retornos crescentes/competição imperfeita na economia, depois da nova organização industrial, da nova teoria de comércio internacional e da nova teoria de crescimento. Desde seu clássico Geography and Trade (1991) até seu último livro em co-autoria com Masahisa Fujita e Anthony Venables (The Spatial Economy, 1999), Krugman construiu um referencial teórico que recolocou o tema da localização da produção no espaço geográfico como uma das preocupações centrais da corrente principal da economia. Partindo da famosa trindade de economias externas de A. Marshall, que induzem à concentração espacial, e incorporando fatos estilizados deduzidos de regularidades empíricas observadas pelas tradicionais teorias urbana, regional e de localização industrial, Krugman construiu um modelo analítico em que a evolução da estrutura espacial da economia é determinada pelo confronto entre, de um lado, forças centrípetas (representadas por linkages, mercados densos, spillovers de conhecimento e outras economias externas puras), que induzem à concentração espacial de atividade econômica, e de outro lado forças centrífugas \{representadas por fatores fixos ou imobilizados, aluguéis e custos de commuting, congestionamento, poluição e outras deseconomias externas puras) que desestimulam a concentração. Entretanto, como a trindade de economias externas marshallianas, segundo Fujita et al. (1999: 18-19), "tem-se mostrado notavelmente difícil da modelar em qualquer sistema formal", e mesmo reconhecendo que todas as forças centrípetas e centrífugas operam no mundo real e têm pelo menos alguma relação com qualquer questão real de geografia econômica, o notável esforço de formalização feito por Krugman e seus co-autores limitou-se a uma fonte de benefícios externos, linkages como força de concentração quando os produtores estão sujeitos tanto a custos de transportes quanto a retornos crescentes, e fatores fixos como força oposta à concentração.

Talvez por isso, e apesar de reconhecerem que haverá, "com certeza, importantes implicações de políticas a partir da nova geografia econômica”, Krugman (1999) e depois Fujita, Krugman \& Venables (1999), sejam tão reticentes quanto às implicações de bem-estar e de políticas. A questão é que, além de terem trabalhado com um único par de forças centrípetas e centrífugas, reconhecem que há externalidades nos dois lados, isto é, no das forças que induzem à concentração e no das que se 
opõem à concentração, de modo que argumentos pró-intervenção baseados em falhas de mercado seriam aplicáveis igualmente aos dois lados, e saber qual externalidade é a mais importante torna-se uma questão de opinião e, como o próprio Krugman (1999:106) reconhece, opinião não oferece bases sólidas para políticas. Por isso, Fujita, Krugman \& Venables ressalvam corretamente que só depois que o enfoque da NGE estiver solidamente apoiado em termos teóricos e empíricos é que se poderá especular quanto a implicações de políticas. Afinal, lembram eles, "um dos objetivos principais da economia é oferecer orientação de política” (p. 348). Mas é curioso notar, nos trabalhos de Krugman, a diferença entre o Krugman "formalizador" e o Krugman, digamos, “economista pop”. Enquanto o formalizador é contido, frugal no que diz respeito a deduzir implicações de políticas, o pop é pródigo em recomendações até, pasmem, de política industrial. Mesmo em Geography and Trade ele admire que algum estímulo (boosterism) envolvendo "incentivos concretos, um tipo de proto-política industrial” pode “(...) pelo menos em princípio, fazer sentido perfeitamente". No seu livro mais pop de todos, Peddling for Prosperity (1994), Krugman insinua que "pequenas intervenções oportunas" são necessárias para não ficar de fora em algumas indústrias importantes (p. 223). Mas onde ele se revela mais abertamente intervencionista é num trabalho publicado em 1993 como capítulo de um livro organizado por D. Salvatore (1993). Nesse trabalho, Krugman considera que há um argumento para política industrial quando"(...) parece que o sucesso de uma indústria é em grande parte uma construção social - que empresas individuais não permanecem ou desaparecem como resultado de seus próprios esforços, mas dependem dos efeitos mutuamente fortalecedores do sucesso de cada uma. Esta é uma maneira não técnica de dizer que economias externas positivas são fundamentais, mas dizendo dessa maneira pode ajudar a fazer com que a ideia pareça menos abstrata. (... ) Na maior parte dos casos, a melhor evidência sobre a importância das economias externas virá de aglomerações geográficas. E tais aglomerações [clusters] geográficas nos ajudarão de fato a definir o que é uma indústria. Porém, simplesmente observar um cluster não é suficiente: é necessário perguntar por que a indústria está aglomerada e avaliar se as economias externas, de natureza tecnológica ou relacionadas a tamanho de mercado, são suficientemente importantes para merecer o apoio do governo" (Krugman, 1993: 176-7). Talvez hoje ele se arrependa de ter escrito essas palavras, ou até renegue o que escreveu, mas o mais provável é que explique que isso foi escrito quando ele ainda se encontrava sob os efeitos dos arroubos intervencionistas provocados pela nova teoria de comércio internacional, cuja ressaca parece ter influenciado também a posterior reticência em derivar implicações de políticas a partir da nova geografia econômica.

Portanto, ainda faltam à nova geografia econômica bases teóricas mais amplas que o par de forças centrípetas/centrífugas utilizado na formalização, e também o suporte de trabalho empírico correspondente. Essa falta de trabalho empírico original é uma das cobranças feitas por P. David (1999) ao comentar o enfoque da nova geografia econômica apresentado por Krugman na conferência anual do Banco Mundial de 1998 e publicado em 1999 (Krugman, 1999). Segundo David, ao 
utilizar fatos estilizados (que ele chama da "factóides") extraídos dos trabalhos clássicos de teoria da localização e de ciência regional, os modelos da NGE geram uma " geografia idealizada da industrialização em que zonas centrais compactas são rodeadas por regiões periféricas nas quais atividades agrícolas e extrativas continuam dominantes", e com isso os modelos da NGE suprimem " detalhes sobre importantes não-homogeneidades que estão presentes em processos locacionais" ( $\mathrm{p}$. 109-10). Entre estes processos, David menciona os "efeitos de spillovers de conhe cimento tecnológico de atividades inovativas, e feedbacks responsáveis por não homogeneidades espaciais na difusão de práticas técnicas e organizacionais”, que são "evidentemente menos prontamente suscetíveis de modelagem matemática mais simples”. Por isso, afirma que é preciso “ estimular esforços empíricos e analíticos para discernir e quantificar a variedade e heterogeneidade de processos interdependentes que conformam as dimensões geográficas do desenvolvimento regional.

Admitir maiores complexidades nas representações paradigmáticas de fenômenos geográficos dinâmicos é um modo de colocar relevantes e interessantes desafios aos model builders, e pode assim resultar em mais rápido avanço de conhecimento empírico e teórico paralelamente" (pp. 110-1).

Mas as críticas de P. David não se resumem às bases empíricas da NGE. Questiona também o excessivo reducionismo dos modelos da NGE diante da multiplicidade de processos dinâmicos que interagem simultaneamente e, diante dessa "realidade complicadora", afirma que "é preciso ir além de modelos heurísticos reduzidos para identificar quais combinações (desses processos) estão operando onde, e como interagem" (p. 111). E prossegue argumentando que:

1. Além das externalidades pelo lado da demanda, enfatizadas por Krugman, há também externalidades pelo lado da oferta, e estas externalidades estão entre as forças potentes que influem na localização da indústria. David (1999: 111-2) menciona três delas: (i) as que afetam os custos relativos de admissão e treinamento de mão-de-obra com diferentes qualificações em mercados de trabalho locais interconectados, cuja modelagem por simulação estocástica mostrou levarem a padrões complexos, auto-organizados, de especialização industrial;

2. (ii) os spillovers localizados de conhecimento que, por métodos semelhantes, mostrou-se resultarem na formação e crescimento de clusters geográficos de empresas intensivas em P \& D, e (iii) as externalidades que afetam insumos de serviços empresariais especializados e outros insumos intangíveis que, por se tornarem relativamente abundantes em alguns locais e serem menos prováveis de se tornar amplamente comercializáveis pela redução dos custos de transportes, parecem ser "comparativamente importantes entre os mecanismos subjacentes à persistência de padrões de localização industrial";

3. Os efeitos de mudanças nos custos de transportes não são geograficamente neutros, de modo que "diferenciais espaciais de crescimento do volume de transportes podem ser um mecanismo potente, auto-reforçador, que favo- 
rece padrões específicos de aglomeração espacial”. Por isso, as vantagens de aglomeração inicial podem ser mais facilmente mantidas durante uma mudança de regime de tecnologia de transportes e comunicações;

4. As vantagens de aglomeração inicial tendem a ser reforçadas por mecanismos de feedback positivo gerados por externalidades relacionadas a linkages e a indivisibilidades técnicas de investimentos em infraestrutura, o que implica atribuir forte historicidade à evolução espacial da economia. B. Arthur (1990, apud Baptista, 1998: 29-31) demonstrou de forma insofismável esse ponto ao elaborar um "modelo de localização industrial no qual empresas escolhendo entre diferentes regiões são atraídas por externalidades de aglomeração, e no qual 'acidente histórico' é um determinante porque as empresas são heterogêneas e entram na indústria aleatoriamente. Os resultados do modelo mostram que, quando não há limite superior ao processo de feedback positivo, uma única região dominante monopolizaria a indústria. Que região seria essa, depende dos fatores que influenciaram as decisões das primeiras entrantes e da aleatoriedade de entrada de empresas". Mas, na realidade, regiões não têm retornos crescentes indefinidamente. Por isso, quando "um limite superior é imposto aos retornos crescentes, devido por exemplo a efeitos de congestionamento decorrentes de aglomeração excessiva, os resultados dependerão da detalhada (embora aleatória) sequência de entrada de empresas. Algumas sequências podem produzir dominância de uma região, enquanto outras levam a soluções nas quais várias regiões participam da indústria e não há tendência à dominação - mesmo no longo prazo. Parece razoável admitir que esta segunda solução é a mais plausível de um ponto de vista empírico", pois como já foi mencionado, as regiões não têm retornos crescentes indefinidamente. Muitos processos dinâmicos na economia são dependentes da trajetória, no sentido de que sua evolução não pode livrar-se da influência de sua história, e esse é um aspecto da realidade que não pode ser ignorado por teóricos a analistas empíricos. Assim, segundo P. David (1999: 113), “é necessário considerar a possibilidade - na verdade, a probabilidade - de que dotações naturais iniciais de certos locais foram subsequentemente ampliadas por mecanismos de feedback positivo, e assim foram transformadas numa sequência de novas e bastante diferentes fontes de vantagens geográficas". E continua, afirmando que "esta é uma visão heuristicamente útil de como a história influi na geografia (... ): o ambiente natural exógeno, tendo surgido primeiro na sequência, é suposto ser dominante na fixação da localização inicial de produção e geração de demanda. A partir daí, uma variedade de processos de feedback positivo entra em operação, fazendo com que fatores de produção fluidos se fixem em torno daqueles locais inicialmente selecionados". Mas essa visão de como a história influi na geografia não se resume na influência das condições iniciais. Segundo David (1999: 113-4), “o timing dos eventos ao longo da trajetória de evolução de uma região também importa para seu desenvolvimento 
espacial”. Sobretudo, “inovações tecnológicas e organizacionais endógenas podem ter fortes e não neutros efeitos geográficos. Além disso, a mudança tecnológica está sujeita à sua própria dinâmica de feedback positivo, e, portanto, pode tornar-se localizada e canalizada em direções que reforçarão algumas características da alocação espacial de recursos ao mesmo tempo que perturba outras";

5. Por fim, e mais importante para os meus propósitos, P. David “acusa” Krugman de ser muito retraído ao considerar as implicações de políticas da NGE, e de subestimar a economia política das estratégias de desenvolvimento regional. Diz, um tanto ironicamente, que os atores líderes do desenvolvimento industrial regional "não devem ser imaginados como quadrilhas de oportunistas ocultos, espreitando para se apoderar de uma teoria em moda como pretexto para perseguir seus interesses privados à custa do interesse público(...) nem como falanges de burocratas caçadores de renda em longínquos países em desenvolvimento" (pp. 114-5). Ao contrário, diz ele, tanto nos EUA quanto na Europa, autoridades municipais, estaduais e regionais "têm sido há muito ativas na implementação de políticas locais e regionais de criação de empregos" e desenvolvimento regional. Essas políticas em geral baseiam-se na concessão de benefícios fiscais, subsídios para infraestrutura, programas de treinamento para trabalhadores, e outros. O que, sim, requer atenção, na visão de P. David, é a análise dos resultados prováveis quando autoridades governamentais de várias localidades ou regiões têm a mesma iniciativa simultaneamente, caracterizando o que ele chama de "torneios locacionais", que podem levar a "falhas regionais na plena exploração de economias de aglomeração" (p. 115). A razão é que, como argumenta David (1999: 115-6), tais disputas locais ou regionais têm estrutura de payoff do tipo torneio, no qual os vencidos ganham pouco ou nada e o ganhador leva tudo. Assim podem surgir ineficiências características de equilíbrios monopolisticamente competitivos, e uma indústria pode ficar espalhada por muitos locais, "nenhum dos quais sendo capaz de alcançar densidade crítica suficientemente rápido para atrair as restantes firmas móveis da indústria”. Além disso, há importantes implicações redistributivas cuja importância não pode ser subestimada, na medida em que as empresas que estão em posição de escolher entre localizações alternativas acabam se apropriando de rendas criadas pela aglomeração. A analogia com a nossa famigerada "guerra fiscal" é imediata. Só para dar um exemplo, será que a fábrica da Ford na Bahia, tirando o "efeito ACM" ${ }^{1}$ é uma localização eficiente? Ou seria uma falha regional provocada por políticas de atração de investimentos? Da mesma forma, as mudanças de fábricas de calçados do Sul e Sudeste para o Nordeste são

\footnotetext{
${ }^{1}$ Referência ao peso da ação política do sena dor Antônio Carlos Magalhães para levar a fábrica da Ford para a Bahia.
} 
motivadas por externalidades ou por vantagens fiscais? Assim, termina David (1999: 116), "reconhecer esses aspectos do papel do Estado evidencia o enorme potencial que existe para equilíbrios múltiplos na alocação geográfica de recursos, e para resultados que podem ser globalmente ineficientes sem alcançar os excessos de congestionamento e externalidades ambientais negativas associadas a gigantes urbanos". Isso significa, ainda segundo David, adicionar "mais uma camada de complexidade aos desafios com que já se defrontam os model builders da nova geografia econômica".

Nada disso, evidentemente, tira o mérito da notável formalização feita por Krugman e seus co-autores, nem eu tive essa intenção. Quis apenas relativizar o avanço feito até agora, mostrando que só uma pequena parte de um conjunto complexo de fatores interrelacionados foi formalizada. E para complicar ainda mais, é preciso reconhecer também que há outras abordagens que, ainda que não sejam inteiramente convincentes em termos teóricos e empíricos, como insinuam Fujita et al. (1999:349), são bastante sugestivas. Por exemplo, Schmitz (1997; 1999) e Schmitz \& Nadvi (1999) sugerem que, embora economias externas locais marshallianas sejam importantes para explicar aglomerações industriais, elas não oferecem uma explicação completa. As economias externas derivadas de cooperação entre empresas e de apoio do setor público constituem um segundo fator explicativo, com a importante diferença de serem deliberadamente perseguidas. A justificativa analítica é a de que economias externas locais não se originam apenas na produção (linkages e spillovers), mas também na distribuição e em outros serviços especializados, comuns em aglomerações industriais. O pleno aproveitamento das economias externas locais incidentais e planejadas levaria à eficiência coletiva, um conceito derivado de Marshall.

Outro enfoque legitimamente sugestivo é o dos geógrafos. Há contribuições relevantes de vários autores nessa abordagem, mas vou destacar um autor que sintetiza bem essas contribuições: A. Scott (1998). Esse autor, a partir do que ele mesmo chama de "amálgama de influências teóricas", elabora uma análise do que considera ser uma "tendência endêmica no capitalismo" à formação de densos clusters localizados de atividades produtivas, com importantes implicações em termos de crescimento, produtividade e comércio internacional. E nessa análise, enfatiza economias externas derivadas de "construção social de ativos político-culturais localizados”, tais como: confiança mútua, entendimentos tácitos, efeitos de aprendizado, vocabulários especializados, formas de conhecimento específico, estruturas de governança (como por exemplo o sistema kanban). Nesse sentido, aproxima-se do enfoque de H. Schmitz, mas é muito mais incisivo na importância que atribui à construção institucional e às políticas públicas na construção de vantagens competitivas localizadas. Sua descrição de um "caso arquétipo" é deliciosamente ilustrativa. Segundo Scott (1998: 389-91), mesmo que haja várias localizações possíveis para uma determinada atividade econômica, pequenos eventos fortuitos podem colocar um local na liderança, quando menos porque começou a crescer mais rápido. Mas um determinado local pode também ser impelido para a fronteira do 
desenvolvimento por decisivos incidentes tecnológicos ou organizacionais. Exemplos históricos bem conhecidos são os dos experimentos gerenciais e organizacionais de H. Ford em Detroit, o desenvolvimento do DC-3 por Donald Douglas em Los Angeles, a constituição da empresa Fairchild de semicondutores no Vale do Silício. Uma vez que algo desse tipo aconteça, são grandes as chances de que o local se consolide e amplie sua liderança, especialmente onde retornos crescentes e efeitos dinâmicos de aprendizado entram em operação. À medida que cresce, o local amplia as economias de aglomeração e induz maior divisão social do trabalho, diversificação econômica e crescentes sinergias locais. Novas qualificações da força de trabalho são estimuladas, tornando o mercado de trabalho local compatível com as necessidades da indústria. A atmosfera industrial local se torna mais densa, surgem características culturais identificáveis por convenções e rotinas próprias das empresas locais. O intercâmbio de informações e os efeitos de aprendizado se intensificam, tornando-se cada vez mais densamente texturizados, aumentando os estímulos a inovações tecnológicas e comerciais. E, finalmente, com o avanço simultâneo de todos esses processos, começa a se materializar um complexo sistema produtivo local ou regional que, por determinado tempo, vai evoluir com base no aproveitamento de economias externas de escala e de escopo. Esse determinado tempo depende, é claro, dos limites à apropriação dos retornos crescentes e do surgimento de outras deseconomias puras de aglomeração. Mas, desde que a liderança adquirida se transforme em forte superioridade competitiva, o local pode engajar-se (lock in) numa trajetória recursiva de desenvolvimento, marcada por sua dependência em relação ao seu próprio passado. Entretanto, a noção de path dependence implica também a possibilidade de ocorrência de pontos críticos de ramificação, decorrentes de eventos em virtude dos quais a economia local ou regional pode mudar para qualquer uma de várias direções possíveis. É nesses momentos que se faz mais importante a intervenção por meio de políticas, de modo a nortear o sistema local para direções mais promissoras no longo prazo. Se essas direções mais promissoras forem seguidas, e não havendo limites à apropriação de retornos crescentes, o sistema produtivo local continuará seu desenvolvimento, transformando-se num centro líder de sua atividade econômica especializada, fazendo com que essa atividade só possa ser exercida num número limitado de contextos locacionais. É assim que, a partir de determinados momentos históricos, lugares como Lancashire, Detroit, Silicon Valley, Hollywood ou a City de Londres tornaram-se praticamente sinônimos de um determinado tipo de produto ou serviço. Mas a evolução pode se dar também de modo inverso, como por exemplo quando mudanças radicais em mercados, tecnologias, qualificações, ambientes institucionais, organização industrial etc. podem deslocar (lock out) sistemas produtivos locais que falham em se engajar rapidamente nas novas condições. O exemplo mais notório deste último caso é o do deslocamento do centro geograficamente dominante da indústria americana de computadores da Rodovia 128, com suas empresas e instituições autárquicas e sistema de produção rígido, para o Vale do Silício, com um sistema industrial mais aberto e flexível, caracterizado por múlti- 
plas e diversas interconexões e ambiente institucional propício a inovação e aprendizado coletivo (Saxenian, 1994).

Com base nessas considerações (sugestivas, como diriam Fujita et al.), Scott propõe um conjunto de medidas de política, nenhuma delas de natureza pecuniária, o que afasta qualquer dilema quanto a possíveis trade-offs entre eficiência econômica e objetivos sociais. Em geral são medidas dirigidas ao sistema produtivo local como um todo visando aproveitar suas variadas externalidades por meio de ações coletivas (cooperação, subordinada a estratégia de governança local), e reorganização (ou construção) institucional. E o que talvez seja mais importante são medidas que não impedem que as forças de mercado eliminem as empresas malsucedidas. Por fim, um terceiro tipo de abordagem é o que focaliza especificamente a dimensão geográfica da atividade inovativa. Também aqui há muitas contribuições relevantes, mas vou limitar-me a mencionar as de Audretsch \& Feldman (1996) e Audretsch (1998). Primeiro, corroborando a intuição de Marshall sobre a relação de causalidade entre a aglomeração industrial e spillovers de conhecimento ("os segredos da profissão deixam de ser segredos e ficam soltos no ar...”), os autores comprovam empiricamente a relação entre spillovers de conhecimento em uma indústria e a aglomeração geográfica da atividade inovativa da indústria. Embora quase tautológicas ("indústrias nas quais os spillovers de conhecimento são prevalecentes têm maior propensão a aglomerar a atividade inovativa do que indústrias nas quais as externalidades de conhecimento são menos importantes"), as conclusões oferecem boa base para as sugestões de política de Audretsch (1998: 18 e 26-7). Afirma ele que "uma vez que o conhecimento é gerado e transmitido mais eficientemente via proximidade local, atividades econômicas baseadas em novo conhecimento têm alta propensão a aglomerar-se numa região geograficamente delimitada. Isso levou a uma mudança fundamental na política pública (...) em direção a um novo conjunto de políticas de capacitação (à) criação e comercialização de conhecimento, como por exemplo políticas de estímulo a P\&D, ao investimento de capital de risco e à criação de novas empresas, todas implementadas ao nível estadual, regional ou mesmo local".

Para terminar esta primeira parte, quero fazer uma ressalva no sentido de deixar claro que, ao discutir esses problemas não tive nem poderia ter qualquer pretensão de simultaneamente apontar soluções. Meu único propósito foi o demostrar que a formalização teórica e o trabalho de verificação empírica ainda têm muito que avançar para oferecer respaldo seguro a intervenções de políticas. Entendo perfeitamente a necessidade de "simplificar as questões de modo a focalizar em apenas algumas das possibilidades", corno justificam Fujita et al. (1999: 346) ou para "manter o modelo interessante", corno diz Krugman (1998: 9). Mas e a "realidade complicadora” de P. David, será que é possível reduzi-la e formalizá-la? Parece claro que não, mas podemos buscar entendê-la melhor complementando a formalização com estudos da história, das instituições, das trajetórias tecnológicas, de eventos que geram bifurcações na evolução de sistemas locais de produção e de inovação, e de contextos sociais, culturais e políticos. Com isso estaríamos nos afastando da visão determinista de Fujita et al. e nos aproximando bastante da realidade complicadora de P. David. 
Definir uma agenda de pesquisas sobre o terna das aglomerações industriais no Brasil é relevante por várias razões. Primeiro, porque a dinâmica da geografia econômica do país tem mostrado o surgimento de novas áreas industriais, em geral cidades médias, nas quais se fortaleceram concentrações geográficas e setoriais de indústrias, paralelamente a uma perda de posição relativa de outras áreas mais tradicionais (Diniz, 1999; 2000). Algumas dessas concentrações têm sido bastante estudadas, como por exemplo o notável "super cluster" da indústria de calçados do Vale dos Sinos (RS), estudado por Schmitz $(1995 ; 1999)$ e outros pesquisadores. Mas muitas outras aglomerações são pouco conhecidas. Segundo, porque resultados parciais e preliminares de algumas pesquisas, das quais se originam alguns trabalhos que estão sendo apresentados neste encontro da ANPEC, já indicam uma surpreendente quantidade e diversidade de aglomerações industriais bem-sucedidas. Terceiro porque, confirmando a opinião de P. David quanto ao conflito entre a teoria e economia política do desenvolvimento regional, o país convive há muitos anos com uma guerra fiscal provocada por políticas estaduais e municipais de atração de investimentos, causando efeitos deletérios sobre as finanças públicas e possíveis falhas regionais na exploração de economias de aglomeração. E por fim, porque o governo federal, seja por reconhecer a relevância do terna, ou por buscar uma via de menor resistência para implementação de políticas, vem procurando definir políticas de apoio a sistemas locais de produção e inovação sem uma base adequada de conhecimento quanto às características das aglomerações existentes.

Portanto, uma agenda de pesquisa sobre aglomerações industriais no Brasil deve conter pelo menos três partes, de preferência sequencialmente: (1) produção de evidência estatística sobre as aglomerações existentes; (2) realização de estudos de casos, e (3) formulação de diretrizes gerais de políticas públicas e ações coletivas adaptáveis caso a caso. Desde logo, porém, vale lembrar que não se trata de propor a criação de aglomerações industriais; em princípio, o mercado é muito mais eficiente que qualquer burocrata para localizar economias externas geograficamente restritas. Nem tampouco é panaceia. Problemas mais gerais de desequilíbrios econômicos regionais devem ser tratados por políticas de âmbito regional ou nacional. Estudos de aglomerações industriais devem visar apenas entender e avaliar empiricamente fenômenos de organização industrial no espaço geográfico.

A produção de evidência estatística sobre aglomerações industriais existentes pode ser feita seguindo o que Krugman (1991) e depois Audretsch \& Feldman (1996) fizeram para os EUA, ou seja, calculando-se coeficientes de Gini locacionais para a produção (ou emprego) industrial e para atividades inovativas. Para os EUA, esses coeficientes foram calculados a partir de bases de dados sobre valor adicionado e sobre inovações por indústria e estado da federação. Esse tipo de dado, por unidade da federação, representa um problema na medida em que não há necessariamente correspondência entre fronteiras políticas e áreas econômicas, como já alertou Krugman (1991: 57). No caso do Brasil, é possível minimizar esse problema trabalhando-se com os dados de emprego por atividade econômica (classificação 
CNAE, 5 dígitos) e por microrregião, fornecidos pela RAIS - Relação Anual de Informações Sociais (Ministério do Trabalho). Com todas as ressalvas que podem ser feitas aos dados da RAIS (só abrangem empregos formais e baseiam-se em auto-classificação), eles na verdade permitem o cálculo de coeficientes de Gini locacionais num nível muito mais desagregado que aquele que seria possível com base nos dados de valor adicionado, à semelhança do que fizeram Krugman (1991) e Audretsch \& Feldman (1996). Trabalhos com base nos dados da RAIS já vêm sendo feitos (ver Saboia, 1999; Diniz, 2000; Brito e Albuquerque, 2000; Suzigan et al., 2000), mas não ainda, ao que me consta, para calcular coeficientes de Gini locacionais. Quanto aos dados sobre concessão de patentes como base para calcular coeficientes de Gini locacionais de atividades inovativas, não os conheço o suficiente para uma avaliação segura. Entretanto, essa base de dados tem sido utilizada com outros propósitos, como por exemplo para avaliar comparativamente o sistema nacional de inovação (Albuquerque, 2000). Resta saber se é possível desagregar os dados do INPI para trabalhar não ao nível dos estados da federação, mas segundo a localização da atividade inovativa (e não da empresa proprietária da patente) de modo a tornar possível caracterizar aglomerações geográficas de atividades inovativas.

Em seguida, a partir da evidência estatística é possível idealizar testes empíricos e nortear estudos de casos que permitam captar distintas características em termos de história e condições iniciais, organização industrial, instituições, formas de governança, contextos sociais, culturais e políticos. Uma fonte adicional de inspiração para esses estudos de caso pode ser dada pelos trabalhos de M. Porter (1990; 1998). E a caracterização dos sistemas locais de produção e de inovação pode seguir o modelo sugerido por Storper \& Harrison (1991, citados por Enright, 1998), abrangendo: extensão da divisão de trabalho, tamanho das unidades individuais de produção, grau de conexão entre as unidades, extensão territorial, e estruturas de governança presentes no sistema (coordenação das relações de poder entre as empresas). A partir dessa caracterização, talvez seja possível elaborar uma tipologia de aglomerações com distintas características produtivas, organizacionais e inovativas.

Por fim, com base no conhecimento gerado pela evidência estatística, pelos trabalhos empíricos e pelos estudos de caso, pode-se pensar em definir políticas públicas e formas de ações coletivas adequadas a cada caso. Mas algumas diretrizes gerais já estão consagradas na literatura: (1) estímulos a P \& D, desenvolvimento de produtos, capacitação em design, treinamento de mão-de-obra, suprimento de serviços industriais especializados (informação sobre mercados, tecnologias, normas e padrões técnicos, regulamentações governamentais, métodos gerenciais modernos, certificação de qualidade, registro de marcas e patentes, e outras), e a atividades de promoção comercial e de marketing; (2) estímulos a cooperação entre empresas sob alguma forma de governança, como por exemplo ações coletivas para criar consórcios de exportação ou de compras de matérias primas, estabelecer instituições locais de prestação de serviços especializados etc., ou iniciativas de cooperação sob a liderança de empresas líderes (Humphrey \& Schmitz, 2000), e (3) estímulos à criação de fóruns locais de discussão e ação estratégica das empre- 
sas visando resolver rapidamente problemas de curto prazo, discutir tendências de longo prazo da indústria e elaborar estratégias para o desenvolvimento local em resposta a crises, novas tendências de mercado, mudanças tecnológicas, desafios e oportunidades.

\section{REFERÊNCIAS}

ALBUQUERQUE, E. (2 000), Domestic patents and developing countries: arguments for their study and data from Brazil (1980-1995). Research Policy 29 (9): 1047-1060.

ARTHUR, W. B. (1990), Silicon Valley locational clusters: when do increasing returns imply monopoly? Mathematical Social Sciences 19: 235-51.

AUDRETSCH, D. B. (1998), Agglomeration and the location of innovative activity. Oxford Review of Economic Policy 14 (2), Summer.

AUDRETSCH, D. B. \& FELDMAN, Maryann P. (1996), R \& D Spillovers and the geography of innovation and production. American Economic Review 86 (3): 630-40.

BAPTISTA, R. (1998), Clusters, innovation and growth: a review of the literature. In G. M. Peter Swann. M. Prevezer \& D. Stout, The Dynamics of Industrial Clustering: international comparison in computing and biotechnology. Oxford: Oxford University Press, cap. 2.

BRITO, J. \& ALBUQUERQUE, E. (2000), Clusters industriais s na economia brasileira: uma análise exploratória a partir dos dados da RAIS. ANPEC, XXVIII Encontro Nacional da Economia. Campinas, 12-15 de dezembro.

CHANDLER, Jr., A.; HAGSTRÖM, P. \& SÖLVELL, Ö., Editors (1998), The Dynamic Firm: The Role of Technology, Strategy, Organization and Regions. Oxford: Oxford University Press.

DAVID, P. A. (1999), Comment em 'The role of geography in development' by P. Krugman. In B. Pleskovic \& J. E. Stiglitz, Annual World Bank Conference on Development Economics - 1998. Washington: The World Bank.

DINIZ, C. C. (1999), A nova configuração urbano-industrial no Brasil. ANPEC, XXVII Encontro Nacional de Economia, Belém, 7-19 de dezembro de 1999. Anais, vol. II.

DINIZ, C. C. (2000), A nova geografia econômica do Brasil: condicionantes e implicações. XII Fórum Nacional, Instituto Nacional de Altos Estudos. Rio de Janeiro, 15-17 de maio.

ENRIGHT, M. J. (1998), Regional cluster, and firm strategy. In Chandler, Jr. et al. (1998), cap. 14.

FUJITA, M.; KRUGMAN, P. \& VENABLES, A. (1999), The Spatial Economy: cities, regions and international trade. Cambridge, MA., The MIT Press.

HUMPHREY, J. \& SCHMITZ, H. (2000), Governance and upgrading: linking industrial cluster and global value chain research. Institute of Developing Studies, University of Sussex, IDS Working Paper, 120.

KRUGMAN, P. (1991), Geography and Trade. Cambridge, MA: MIT Press.

KRUG MAN, P. (1993), The current case for industrial policy, in D. SALVATORE, Editor (1993), cap.7. KRUGMAN, P. (1994), Peddling for Prosperity: economic sense and nonsense in the age of diminished expectations. New York and London: W. W. Norton \& Company.

KRUGMAN, P. (1998), What's new about the new economic geography? Oxford Review of Economic Policy 14 (2), Summer.

KRUGMAN, P. (1999), The role of geography in development. In B. Pleskovic \& J. E. Stiglitz, Annual World Bank Conference in Development Economics - 1998. Washington: The World Bank.

PORTER, M. E. (1990), The Competitive Advantage of Nations. London: McMillan.

PORTER, M. E. (1998), Clusters and the new economics of competition. Harvard Business Review, November/December.

SABOIA, J. (1999), Desconcentração industrial no Brasil nos anos 90: um enfoque regional. ANPEC, XXVII Encontro Nacional de Economia, Belém, 7-19 de dezembro de 1999. Anais, vol. II. 
SALVATORE, D., Editor (1993), Protectionism and World Welfare. Cambridge: Cambridge University Press.

SAXENIAN, A. (199 4), Regional Advantage: Culture and Competition in Sillicon Valley and Route 128. Cambridge, MA.: Harvard University Press.

SCHMITZ, H. (1995), Small shoemakers and fordist giants: tale of a supercluster. World Development, $23(1)$.

SCHMITZ, H. (1997), Collective efficiency and increasing returns. IDS Working Paper 50. Institute of Development Studies, University of Sussex, Brighton.

SCHMITZ, H. (1999), Global competition and local cooperation: success and failure in the Sinos Valley, Brazil. World Development, 27 (9).

SCHMITZ, H. \& NADVI, K. (1999), Clustering and industrialization: Introduction. World Development, $27(9)$.

SCOTT, A. (1998), The geographic foundations of industrial performance. In CHANDLER, Jr. et al., Editors (1998), cap. 16.

STORPER, M. \& HARRISON, B. (1991), Flexibility, hierarchy and regional development: the changing structures of industrial production systems and their forms of governance in the 1990s. Research Policy, 20 (5).

SUZIGAN, W.; FURTADO, J.; GARCIA, R. \& SAMPAIO, S. E. K. (2000), Aglomerações industriais no Estado de São Paulo. ANPEC, XXVIII Encontro Nacional de Economia. Campinas, 12-15 de dezembro. 